Academic Journal of Social Sciences (AJSS)

Vol. 5, Issue 4 (October - December 2021) PP. 419 - 435

\title{
Impact of Student Wellness on Academic Performance with Mediating Role of Learning Environment
}

\section{Raja Irfan Sabir ${ }^{1, *}$, Muhammad Bilal Majid ${ }^{2}$ and Khansa Masood $^{3}$}

\begin{abstract}
The main objective of this study was to investigate the impact of student wellness on academic performance mediated by the learning environment. This research has been conducted in the universities of Sahiwal region and 678 questionnaires were distributed. 650 valid responses were returned backed to the researchers and the response rate was 96\%. Theory of Wellness and Theory of Educational Productivity has been used in this study to answer the research questions. A quantitative research approach has been used and data were collected through a questionnaire survey with adapted research tools. The findings of this study showed that student wellness and learning environment have a significant impact on student academic performance. This study found that the learning environment mediated the relationship between student wellness and student academic performance. The practical implication of this study is for universities/educational institutions to make policies, which are best at a national level to determine student wellness with regards to student academic performance in Pakistan as well as less developed countries. The originality of this study is that this study is one of the rare studies that investigate the impact of student wellness on academic performance with the mediating role of the learning environment. This research caters to the problems faced by students, by providing experts or institutions with the right direction for creating a conducive environment for students' experiences, wellness, positive learning, and long-life success.
\end{abstract}

Keywords: Academic Performance, Student Wellness, Learning Environment, University Students, Educational Productivity.

\footnotetext{
${ }^{1}$ Faculty of Management Studies, University of Central Punjab, Lahore, Punjab, Pakistan.

2 Department of Business \& Management, Universiti Sultan Zainal Abidin, Terengganu, Malaysia. Corresponding Author: si2686@putra.unisza.edu.my ${ }^{3}$ School of Professional Development, University of Management and Technology, Lahore, Punjab, Pakistan.
} 


\section{Introduction}

Every educational institution relies on students as a vital resource. Student academic achievement is inextricably linked to the country's social and economical development. The performance of students is critical in developing exceptional graduates who will serve the country (Norhadiya, 2016). During COVID-19, the impact of voluntary attendance patterns on the health and academic performance of first-year medical students was studied (Salzman et al., 2021 ). Students' academic performance estimation has become a broad spectrum in past research, as it is the focus of the scholarly composition. Students' performance is affected by various factors, ranging from social, mental, financial factors to individual demographics, etc (Maharaj, 2018). These components highly affect students' output; however, the influence varies from person to person (Mlambo, 2017). Most studies on students ${ }^{\text {ee }}$ academic performance have been led concerning such issues as sexual orientation distinction, instructor's training and showing style, class condition and financial components (Mushtaq \& Khan, 2016). To supervise and understand feelings is critical to gain achievement in different relational and vocation-related fields. By convention, educational institutions have focused solely on normal and phonetic insight, without paying considerable regard to other types of knowledge (Mann et al., 2021). Academic performance has emerged as one of the most important determinants of early school dropout (Araque, 2014). In addition, it has been shown that poor school performance provides other important elements, such as Socioeconomic status and demography, rude behaviors, social life in family and school (Pearson et al., 2000), and mental health disorders (Esch et al., 2014).

Somehow, a low level of student anxiety is associated with better performance (Ali et al., 2013), while maximum frustration and anxiety can affect students' education and achievement of their target. Mashach (1999) has shown that stress and the chance of failure are the two major speculative elements that promote burnout (Gillespie, 2002). In particular, stress indicates the increase in burnout symptoms, especially concerning intellectual fatigue (Richardsen, 1993).

The expression 'wellness and prosperity' or 'prosperity and wellness' is picking up noteworthiness and helpfulness in wellness advancement and general wellness. The belief system of health for an effective adjusted presence consolidates the cognizant, self-coordinated exertion of deep-rooted learning and basic leadership (Evans et al., 2007). Social wellness (SW) being vital talked about wellness wheel empowers a person to get by in the general public through communication with companions, family, associates, and the whole group. Great relational abilities empower a person to make an emotionally supportive network that offers quality to the family, reinforces one's capacity to work, presents regard to others, and creates a significant association with individuals (Rehana, 2014).

The importance of wellness has grown since the turn of the twenty-first century. "Wellness is a proactive approach aimed at achieving the highest levels of physical, social, and emotional functioning" (Todd, 2011). Investigating the influence of the factors driving university student wellness is a critical avenue to explain because students are increasingly moving into the job force while keeping responsibilities, which tends to blur the formerly clear line between their 
personal, scholastic, and professional life (Geotzel, 2014). Spur (2016) asserts that health and educational authorities are concerned in promoting the health and wellness of future generations; nevertheless, research on student wellness is scarce. Previous studies on student academic performance consider such issues as teacher's education, gender difference, students wellness, teaching style, social factor, economic factor, class environment, and family educational background. However, academic performance is greatly affected by the students' low wellness and lack of proper learning conditions (Mushtaq, 2012) and the academic performance of students in Pakistan is declining due to low wellness and poor learning conditions (Fatima, 20121).

The main objective of this research was to analyze the impact of Student Wellness on Academic Performance and to examine the mediating effect of the Learning Environment on the relationship between Student Wellness and Academic Performance. This will be achieved by addressing the following questions.

Q1) Does Student Wellness significantly and positively impact Academic Performance?

Q2) Does Student Wellness significantly and positively impact Learning Environment?

Q3) Does Learning Environment significantly and positively impact Academic Performance?

Q4) Does Learning Environment Mediate the relationship between Student Wellness and Academic Performance?

\section{Literature Review}

\subsection{Academic Performance}

Academic performance is crucial for all understudies as a tool for living a successful life. Guardians are concerned about their children's academic performance since they trust great academic outcomes will give more professional decisions and employer stability (Griggs, 2017). To gather students who are educated grabbed high scores on government-endorsed tests than those who are gatekeepers were not taught (Topor, 2010). Students who participated can get more in-depth conversations with their students on the homework assignment practices, and information learned at university. They can better help their children in their work and take an interest at University (Marica, 2016). There is an extent of segments that affect the idea of execution of the students (Abbas, 2015).

Henerad, (2008) utilized CGPA to quantify students' execution because their primary concentrates on the students' execution for the exact semester. Some exceptional professionals used test impacts or before-year results since they are thinking about execution for the particular subject or year (Najah, 2009).

Tahir (2006) additionally, explained that the students' execution is particularly reliant on SEB (financial background) according to their declaration, "university understudies' level of execution is with truthfully essential differentiation, associated with their gender, audit level, college area, college writes, students compose and financial foundation. Students' anxiety impacts their scholastic execution. Walton (2011) discovered that feeble understudies improve the situation when gathered with other powerless understudies. In this investigation, the specialist 
will utilize two things (premium and study propensities) to gauge the scholarly execution of the university students.

\subsection{Student Wellness}

The relative definitions of well-being are assessed in this study: Well-being is "an eparchy of total mental wellness and not just the deficiency of disorder or illness" (El Ansari \& Stock, 2010; Nemec et al., 2019). It is normally indicating a healthy comparison of spirit, body, and mind that leads to general well-being. Well-being is now widely used as a term for health professionals and the public. Instead of extensive welfare research, there is no consensus on what constitutes well-being (Corbin, 2009). For years, health professionals, scientists, and academics have explained why people are well-being. It is widely acknowledged as the modern welfare mobility's guru (Mayer, 2006), defines well-being as "erotic procedure stirring where students incline idealistic and produce decisions to make their lives more successful".

La Fountaine (2006) reviewed various mechanisms and find that well-being is "a lifestyle focused on excellent health \& wellness, in which the staple and soul are integrated of the human and natural community." In recent periods Burgess (2006) has defined well-being as "an integrated and evolutionary level of function that focuses on enhancing potential based on ownership". Although previous definitions of well-being vary according to the perspective of health professionals, all indicate that well-being is the optimal functioning of all human systems. It was up to mortals to form the action to achieve their utmost possibility through the right selection. These welfare procedures have exclusively been devoted to in the literature as "magnitude" or "subparts".

McLeod (2012) suggested that the majority of welfare aspects may vary from 2 to 7 or more, depending on the perspective from which various authors define well-being. However, they suggested that the fundamental aspects of personal well-being are related to a person's different dimensions. Other proportions, such as work and the situation, were the features of the environment that grasped the well-being of the students and were, therefore, less proximal. The World Health Organization defines wellness as "a state of complete physical, mental and social wellbeing and not merely an absence of disease or infirmity" (Van Lingen, 2011). Even though this definition is at the heart of the modern understanding of wellness, the researcher believes it is unrealistic because it is nearly impossible for an individual to achieve perfect wellness in all domains. As a result, according to Edlin (2016), a revised definition of wellness was proposed, emphasizing the individual's responsibility for total wellness through lifestyle choices.

\subsection{Learning Environment}

All the more particularly, this study expects to recognize and break down components that influence the nature of students' academic performance. Institutions of higher education are mind complex, decentralized institutions that depend on the particular information and aptitudes of the workforce and staff for the greater part of their everyday operations (Peter, 2014). Although our organization's advantage from this ability, basic downsides of such decentralization and specialization incorporate territoriality, "storehouse" considering, and the nearness 
crosswise over grounds of key people who might be ignorant of the gifts and premiums of experts in different divisions. Regular crosswise over institutional sorts, this circumstance can be particularly risky in substantial foundations (Robert, 2013). Universities can notify spots where betterment in learning and team building to enhance the opportunity that their seekers will attain their educational goals (Kuh, 2009). Students can be offered higher quality learning approaches from in-depth studies and perceptions of the learning environment that supports this learning (Prosser, 2003) to improve their learning mechanism.

Several studies have underscored the impact of learning conditions on student performance (Sammons et al., 2011). The physical learning condition can likewise affect student exertion through a few components. In addition, Reilly et al. (2016) has determined that students' performance is associated with the learning environment and find that a healthy and calm environment is an important factor. The Learning condition is the viable variable for students and has a positive association with student academic performance (Korhonen, 2014).

\subsection{Theory of Educational Productivity}

Investigation of learning conditions, particularly during the past 40 years, has rapidly drawn the premiums of informational researchers. Specifically, every theoretical model joins properties of the student, the learning condition, and the idea of bearing the understudy gets have projected speculative models to illustrate associations accessible between learning components and students' educational results. In particular, each hypothetical model circuits properties of the students, the learning condition, and the lead the students get (Walberg, 1981). Walberg's investigation perceived nine key factors that influence instructive results as students restrain/earlier accomplishment, inspiration, age/formative level, a measure of heading, nature of administering, classroom condition, home condition, peer get-together, and preamble to extensive correspondences outside of school Further, mental qualities of individual students and their quick mental conditions influence educational results (Reynolds \& Walberg, 1992).

\subsection{Theory of Wellness}

Wellness is a condition of consistent sentiment prosperity and prosperity is a state accomplished by being in a free stream of vitality, adjustment between Mind, Emotions, Physique, and Soul. In this research, wellness including its two dimensions social wellness and academic wellness is measured with the relationship of the learning environment and student academic performance. Wellness has a significant and positive relationship with other variables. At each minute in life, we confront a circumstance where we settle on a decision. This decision could be useful or damaging, positive or negative, for congruity and adjust or against amicability and adjust, towards request and wellness or far from request and wellness. To recapture wellness, it is vital to advance towards congruity and adjust. Wellness can always hold on in the mix of social wellness and academic wellness (Nurs, 2009).

\subsection{Theory of Educational Productivity}

Walberg's (1981) Theory of Educational Productivity puts forward that the mental qualities of individual students and their quick mental conditions influence educational results. 
Further, his investigation perceived nine key factors that influence instructive results as students' prior achievement, inspiration, age, the quantity of instruction, quality of instructional experience, classroom or school environment, home environment, peer group environment, and mass media.

Based upon the thorough literature review we have come up with the following hypotheses and conceptual framwork of the study.

H1: There is a positive and significant relationship between student wellness and student academic performance.

H2: There is a positive and significant relationship between student wellness and the learning environment.

H3: There is a positive and significant relationship between the learning environment and student academic performance.

H4: Learning environment mediates the relationship between student wellness and student academic performance.

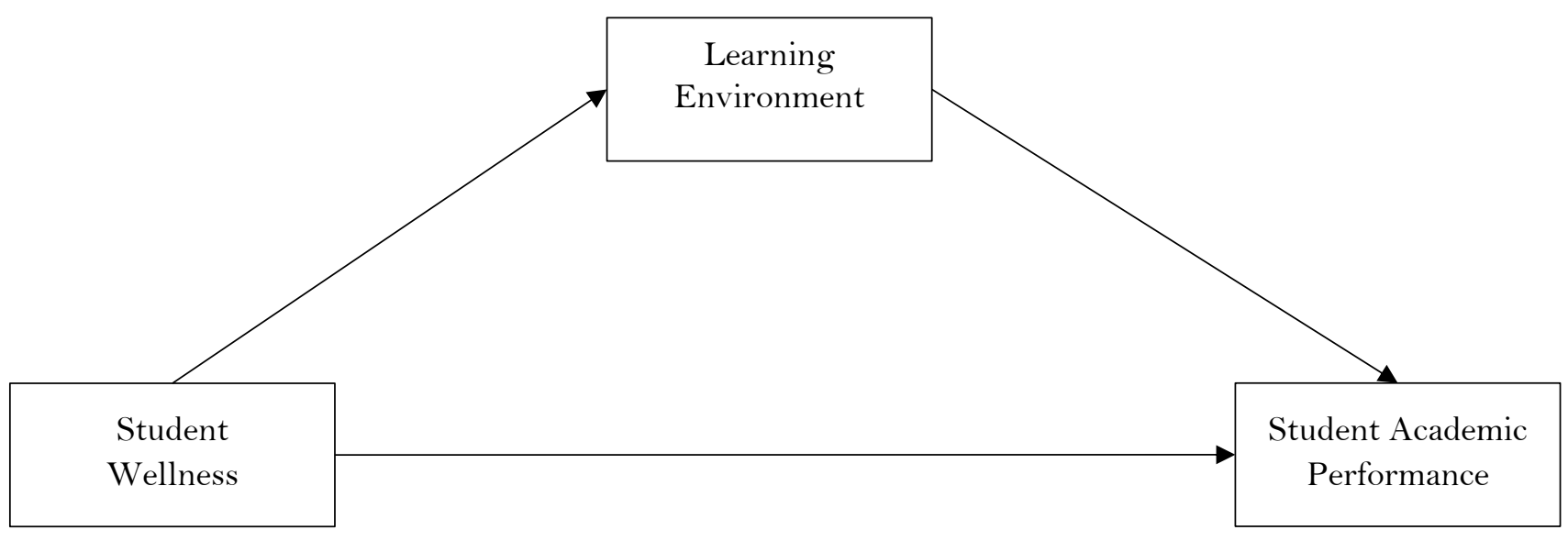

Figure 1: Conceptual Framework

\section{Research Methodology}

\subsection{Research Approach \& Nature}

The researcher has adopted the positivist approach and deductive because it is based on the testing of hypotheses and checked the causal effect relationship among the variables.

\subsection{Sampling Technique \& Target Population}

A structured questionnaire survey was used to collect the data through the purposive sampling technique, the main goal of purposive sampling is to focus on the wellness characteristics of a target population. 678 questionnaires were distributed. Among these,650 valid responses were returned backed to the researchers and the response rate was $96 \%$. The 
target population of this study was the university undergraduate and graduate business students of the Sahiwal Division. The researcher selected the Sahiwal Division because it is an educational city but the literacy rate is 58\% (Pakistan Economic Survey, 2017-18). The target population of this study was the university students of COMSATS University Islamabad, Sahiwal campus, University of Sahiwal, PMAS Arid Agriculture University, Sahiwal campus, GCUF, Sahiwal campus, the University of Okara, and the University of Lahore (Pakpattan Campus) of Sahiwal Division.

\subsection{Sample Size \& Collection Method}

A method that is used to select the sample size is the number of items that are used to measure the variables was multiplied by 10 (Pallant, 2007). The number of items to measure variables was 35 , and therefore minimum sample size was 350 at the $95 \%$ level of confidence and keeping the $5 \%$ error margin. But the researchers took a sample size of 678 for more generalizability.

Every respondent in the study was required to complete three measures: Student wellness (Student Wellbeing Survey, 2014) was measured with two elements academic wellness and social wellness, Student academic performance (Gargallo \& Bernardo, 2012) was measured by using two elements interest and study habits of university students and Learning environment (Debbie et al., 2007) was measured by using two elements (classroom positive and diversity values). All of the scales were measured on a 5-point Likert scale, with 1 to 5 being the highest. For data analysis, AMOS was used to do confirmatory factor analysis and structural equation modeling, with hypotheses approved based on path coefficients.

\section{Results and Findings}

\subsection{Demographics}

A total of 650 questionnaires were filled out by university students out of which $72 \%$ were male and $28 \%$ were female respondents.

Table 1: Gender

\begin{tabular}{ccccc}
\hline & Frequency & Percent & Valid Percent & Cumulative Percent \\
\hline Male & 451 & 71.8 & 71.8 & 71.8 \\
Female & 177 & 28.2 & 28.2 & 100 \\
\hline Total & 628 & 100.0 & 100.0 & \\
\hline
\end{tabular}

\subsection{Reliability Analysis}

It is considered that for better internal consistency the value of the variables must be greater than 0.70 (Kaplan \& Kaiser, 2006). The consistency of the questionnaire has been analyzed by calculating Cronbach coefficient alpha (=0.732). The calculating amount of consistency is accepted. Individually student wellness questionnaire Cronbach coefficient alpha is $(=0.703)$. Learning environment questionnaire Cronbach coefficient alpha is $(=0.700)$. And in the last, student academic performance questionnaire result is alpha $(=0.732)$. 
Table 2: Reliability Analysis

\begin{tabular}{cccc}
\hline S. No. & Variables & Cronbach's Alpha & Items \\
\hline 1 & Student Wellness & 0.703 & 14 \\
2 & Academic Performance & 0.732 & 14 \\
3 & Learning Environment & 0.700 & 15 \\
\hline
\end{tabular}

\subsection{Measurement Model}

In present research AMOS has been utilized to develop the evaluation paradigm to ensure consistency, the reliability of the scale is not sufficient to illustrate through Cronbach Alpha value only, so for better reliability, the researcher utilized the CFA in the evaluation paradigm (Gefens et al., 2000).

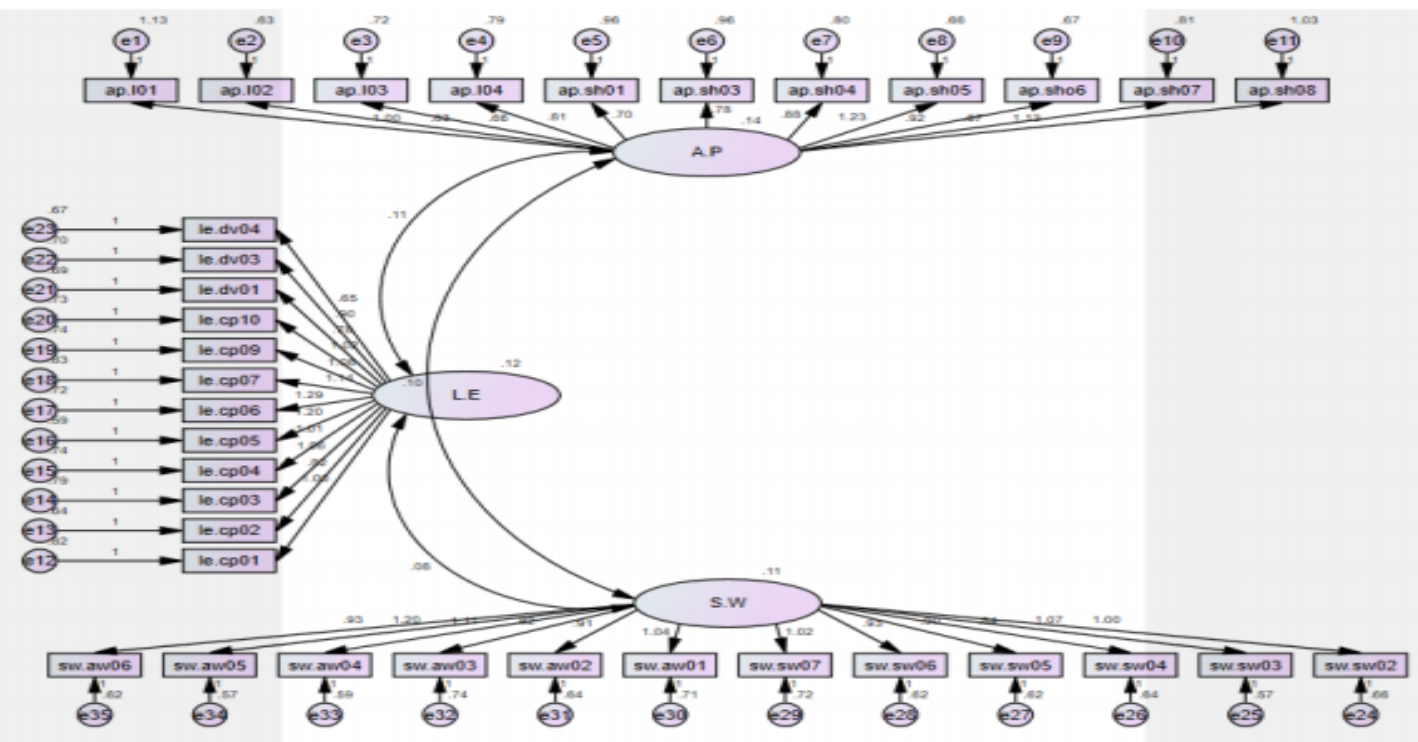

Figure 2: Measurement Model

The results of CFA confirmed that the items used to measure the latent variables are good indicators for the constructs but some of the items are not fulfilling the convergent validity criteria so these were removed. The items that were removed to measure the latent variables are API05, AP.SHo2, AP.SH09, LE.CP08, LE.DV02, LE.DV05, SW.SW01 and SW.SW07. CFA can be used to investigate the cause loading to every experimental variable on the underlying variable (Byrne, 2010). This allows the assessment of construct in provisions of discriminant validity and converging validity (Klinea, 2011). Convergent validity is apprehensive with assessing the amount of an affirmative association between scale items developed to evaluate the same build. On the other hand, convergent validity corroborates to evaluate that ought to be supposedly associated with certainty relation (Nahmias, 2007). To achieve the convergent validity values of all the variables is required more than 0.5. In the current research values of factor, loadings are more than the required values. 


\subsubsection{Convergent Validity}

The results of CFA confirmed that the items used to measure the latent variables are good indicators for the constructs but some of the items are not fulfilling the convergent validity criteria so these are removed. The items which are removed to measure the latent variables are API05, AP.SHo2, AP.SH09, LE.CP08, LE.DV02, LE.DV05, SW.SW01 and SW.SWo7. CFA can be used to investigate the cause loading to every experimental variable on the underlying variable (Byrne, 2010). This allows the assessment of construct in provisions of discriminant validity and converging validity (Klinea, 2011). Convergent validity is apprehensive with assessing the amount of an affirmative association between scale items developed to evaluate the same build.

Table 3: Convergent Validity

\begin{tabular}{|c|c|c|c|c|}
\hline Variable & Measure & Factor loading & AVE & $\sqrt{A V E}$ \\
\hline \multirow[t]{11}{*}{ Academic performance } & AP.IO1 & 0.675 & 0.5131 & 0.7163 \\
\hline & AP.IO2 & 0.763 & & \\
\hline & AP.I03 & 0.721 & & \\
\hline & AP.I04 & 0.781 & & \\
\hline & AP.SHo1 & 0.660 & & \\
\hline & AP.SHo3 & 0.672 & & \\
\hline & AP.SHo4 & 0.619 & & \\
\hline & AP.SH05 & 0.741 & & \\
\hline & AP.SHo6 & 0.673 & & \\
\hline & AP.SHo7 & 0.789 & & \\
\hline & AP.SHo8 & 0.763 & & \\
\hline \multirow[t]{12}{*}{ Learning Environment } & LE.CPO1 & 0.672 & 0.5039 & 0.7099 \\
\hline & LE.CPO2 & 0.789 & & \\
\hline & LE.CP03 & 0.721 & & \\
\hline & LE.CPO4 & 0.632 & & \\
\hline & LE.CPO5 & 0.762 & & \\
\hline & LE.CPO6 & 0.741 & & \\
\hline & LE.CPO7 & 0.652 & & \\
\hline & LE.CPo9 & 0.672 & & \\
\hline & LE.CP10 & 0.649 & & \\
\hline & LE.DVO 1 & 0.669 & & \\
\hline & LE.DVo3 & 0.776 & & \\
\hline & LE.DVo4 & 0.759 & & \\
\hline \multirow[t]{12}{*}{ Student Wellness } & SW.SWO2 & 0.687 & 0.5125 & 0.7158 \\
\hline & SW.SW03 & 0.721 & & \\
\hline & SW.SW04 & 0.738 & & \\
\hline & SW.SW05 & 0.711 & & \\
\hline & SW.SW06 & 0.679 & & \\
\hline & SW.AWo1 & 0.719 & & \\
\hline & SW.AWO2 & 0.687 & & \\
\hline & SW.AW03 & 0.707 & & \\
\hline & SW.AW04 & 0.742 & & \\
\hline & SW.AW05 & 0.719 & & \\
\hline & SW.AW06 & 0.742 & & \\
\hline & SW.AW07 & 0.735 & & \\
\hline
\end{tabular}


On the other hand, convergent validity corroborates to evaluate that ought to be supposedly associated with certainty relation (Nahmias, 2007). To achieve the convergent validity values of all the variables is required more than 0.5. In the current research values of factor, loadings are more than the required values.

\subsubsection{Discriminant Validity}

To assess discriminant validity, the square root of AVE should be greater than the construct's correlation value (Hair et al., 2021). The value of the squared root of AVE must be bigger than the squared correlation between the variables to satisfy the scale's validity. All of the bold values in the table are AVE values.

Table 4: Discriminant Validity

\begin{tabular}{cccc}
\hline Variable & Academic Performance & Learning Environment & Student Wellness \\
\hline Academic performance & 0.7163 & 0.529 & 0.482 \\
Learning Environment & & 0.7099 & 0.495 \\
Student Wellness & & & 0.7158 \\
\hline
\end{tabular}

\subsection{Structural Model}

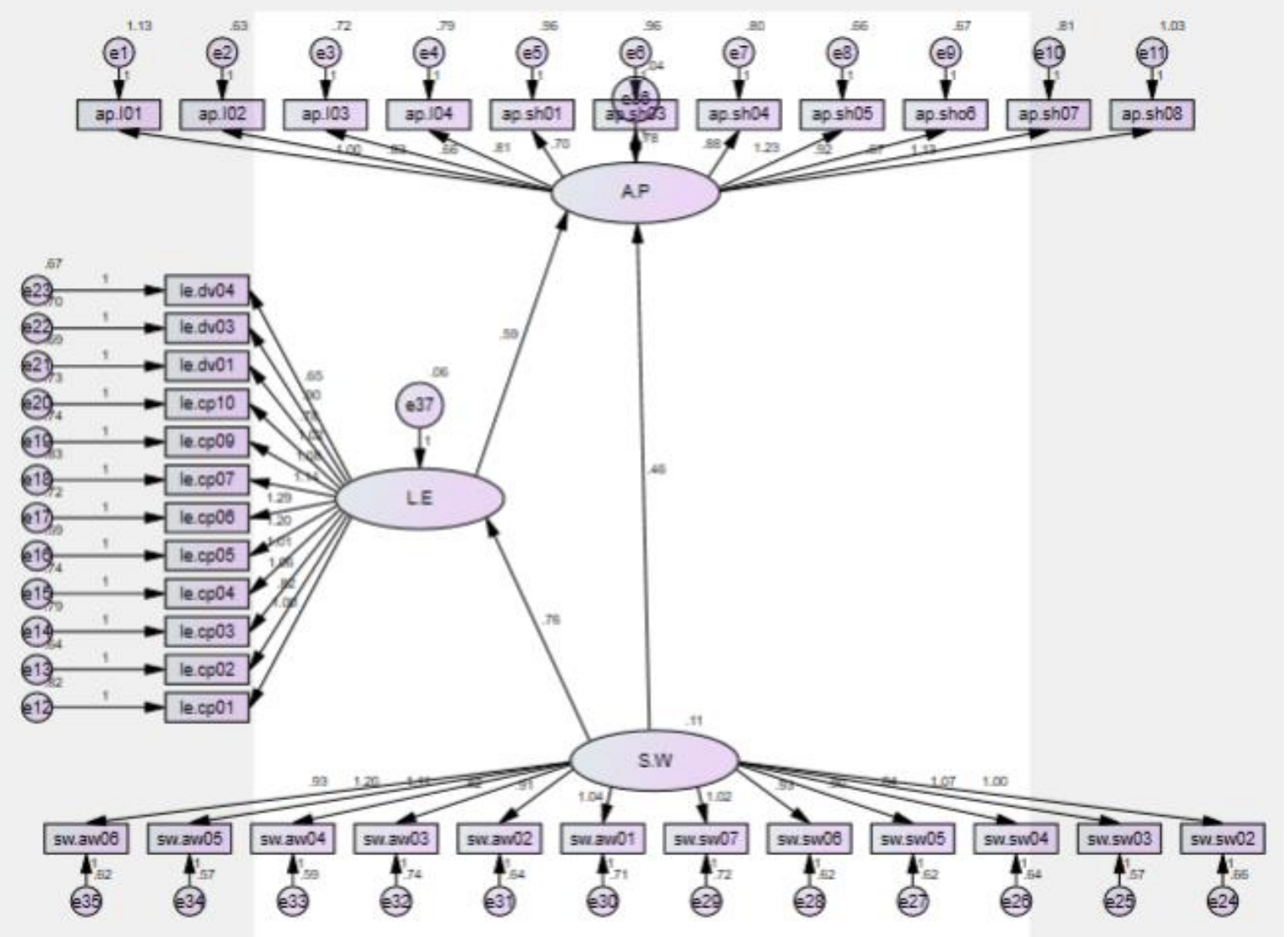

Figure 4.2: Structural Model 
Model fitness is a most essential part of the SEM analysis. It is based on the validity of empirical figures, enormous studies were conducted and diverse paradigms were anticipated for the fitness model. In the current research, the commonly used fitness models index has been examined. SEM provides a measurement of erroring the models and it is beneficial as it describes the link among the variables (Baron \& Kenny, 1986).

Table 5 shows the fitness indexes where we study results have achieved the minimum cutoff values. Table 6 provides the path analysis and the justification regarding the integrity of the paradigm. As indicated by Shah and Goldstein (2006), they review the 92 research articles identified with model wellness and clarified that the estimations of these files are going distinctively in various research papers as referenced above in the table. In this way, in present research all the indicators including the incentive inside the prescribed range so modular are fit.

The Table 6 shows a coefficient path to reject or accept the proposed hypotheses, $\mathrm{H} 2$ : $=0.763, \mathrm{t}=5.507$,p0.0001) social wellness enhances the learning environment of the business undergraduate and graduate students of the universities in the Sahiwal region. $\mathrm{H} 1$ : $\beta=0.462$, $\mathrm{t}=3.295$, p0.0001, social wellness has a significant impact on student academic performance because its results showed their significance.H3: $\beta=0.586, t=3.876$,p0.0001, the learning environment has a significant impact on student academic performance which is shown by their results.

Table 5: Model Fitness Indexes

\begin{tabular}{ccc}
\hline Fit idiocies & $\begin{array}{c}\text { Reported values in Literature } \\
\text { (Shah \& Goldstein, 2005) }\end{array}$ & Actual Values \\
\hline GFI & Range $(0.75-0.99)$ & 0.921 \\
RMR & $(0.01-0.14)$ & 0.093 \\
NFI & $(0.72-0.98)$ & 0.924 \\
AGFI & $(0.63-0.97)$ & 0.721 \\
RMSEA & $(0.00-0.13)$ & 0.082 \\
IFI & $(0.88-0.98)$ & 0.936 \\
CFI & $(0.88-1.00)$ & 0.956 \\
TLI & $(0.73-1.07)$ & 0.843 \\
\hline
\end{tabular}

Table 6: Coefficient Path

\begin{tabular}{|c|c|c|c|c|}
\hline Causal path & Estimate & S.E & C.R & $\mathbf{P}$ \\
\hline $\mathrm{LE} \leftarrow \mathrm{S} . \mathrm{W}$ & 0.763 & 0.139 & 5.507 & ***** \\
\hline $\mathrm{AP} \leftarrow \mathrm{S} . \mathrm{W}$ & 0.462 & 0.140 & 3.295 & **** \\
\hline $\mathrm{AP} \leftarrow \mathrm{LE}$ & 0.586 & 0.151 & 3.876 & ***** \\
\hline
\end{tabular}

\subsubsection{SEM Path Analyses (Mediations)}

Student wellness has a total effect of 0.909 on academic performance which includes 0.462 direct effects and 0.447 indirect effects on academic performance. It shows that the learning 
environment is mediating the relationship between student wellness and student academic performance.

Table 7: Total Effect (Mediation)

\begin{tabular}{cccc}
\hline & SW & LE & AP \\
\hline LE & 0.763 & 0.000 & 0.000 \\
AP & 0.909 & 0.586 & 0.000 \\
\hline
\end{tabular}

Table 8: Direct Effect (Mediation)

\begin{tabular}{cccc}
\hline & SW & LE & AP \\
\hline LE & 0.763 & 0.000 & 0.000 \\
AP & 0.462 & 0.586 & 0.000 \\
\hline
\end{tabular}

Table 9: Indirect Effect (Mediation)

\begin{tabular}{cccc}
\hline & SW & LE & AP \\
\hline LE & 0.000 & 0.000 & 0.000 \\
AP & 0.447 & 0.000 & 0.000 \\
\hline
\end{tabular}

\section{Discussion and Conclusion}

This study analyzed the impact of student wellness on student academic performance with the mediating role of a learning environment.

The findings of this study support the previous research in general. Previous literature suggested that student wellness greatly affects students' academic performance (Chen \& Tjosvold, 2005). Previous research also suggested that the learning environment has a positive effect on student academic performance of business studies. This research was conducted primarily to examine the wellness of business students at undergraduate and graduate levels in different universities of the Sahiwal region. Secondly, this study was conducted to investigate what kind of relationship exists between student wellness and student academic performance with mediating role of a learning environment. So, the results of this study proved that student wellness has a great effect on the performance of students in business studies.

The first research question of this study was to answer, "Does student wellness significantly and positively impact their academic performance?” Student wellness has a direct contribution to the academic success of students in universities. Studies have appeared in scholastic execution dependent on sexual orientation, student wellbeing, and academic program (DeBerard et al., 2017). Wellness has not been widely examined in relationship to academic achievement. A few studies have appeared solid relationship between wellness and academic achievement (Richards \& Casey, 2014). In the present examination, I found there is a solid connection between's student wellness and academic performance. So, the results indicated that student wellness has a significant effect on the academic performance of business graduates and undergraduates in the universities of the Sahiwal region. 
The second research question was to answer, "Does student wellness significantly and positively impact the learning environment?" Well-being plays role in a learning environment. The wellness of students and their relationship among themselves creates a healthy learning environment. Universities can arrange games and sports events to enhance the opportunity of the relationship between students'well-being and learning environment to attain their educational goals (Kuh, 2009). There is a strong relationship between student wellness and learning environment as shown in the results.

The third research question of this study was to find out the answer of "Does Learning Environment significantly and positively impact on their academic performance?" Several studies have emphasized the effect of the learning environment on student performance (Sammons et al., 2011). The physical learning condition can likewise affect understudy effort through a few systems. In the first place, enhancing natural conditions may convey significant additions to students' accomplishments by diminishing diversions and missed university classes (Mendell \& Heath, 2014). Second, assurance can be enhanced if structures are in great condition. In addition, Reilly et al. (2016) studies determine that students' performance is associated with a learning environment and find that a healthy and calm environment is an important factor. The result showed that the learning environment helped the students to improve their academic performance.

The last research question of this research was to answer "Does learning environment mediates the relationship between student wellness and academic performance?” Student learning is linked with a learning environment, while the learning environment affects academic performance and student wellness. Wiersira (2004) suggests that teachers can improve student learning by introducing a student-oriented mechanism in which they have the opportunity to actively participate in learning. Julia (2016) argued that students' viewpoint of the study environment affected their learning approaches. The result showed that the learning environment was positively mediated the relationship between student wellness and learning environment. So, all the answers to the questions were successfully answered in this study.

\section{Limitations, Future Directions and Study Implications}

A quantitative approach was used to test the theory of wellness and the theory of educational productivity. Data were collected through a questionnaire survey from the Sahiwal Region, Pakistan. Business undergraduate and graduate students of the Universities in the Sahiwal region were the respondents of the study. Considering the future directions such as a mixed approach (qualitative and quantitative) can be used to conduct the study. Data can be collected from other regions of the Punjab, Pakistan. In the future respondents can be from the other departments as the target population to conduct this study and finally learning environment can be studied as an independent variable and student academic performance can be a dependent variable.

The findings of this study can be used by universities and educational institutions to design policies that are most effective at the national level in determining student wellness in terms of academic performance in Pakistan and other developing countries. This research can 
address the issues that students confront by pointing specialists or institutions in the appropriate path for building an environment that is conducive to students' experiences, wellness, positive learning, and long-term success.

It will also aid supervisors, managers, and lecturers in acknowledging the obstacles that students confront in both their personal and professional lives. Furthermore, the current research could aid in raising awareness of the importance of wellness management among graduate and undergraduate business students. In terms of graduate student wellness, the study provides valuable insight and understanding for the university as well as managers within organizations. Finally, this research will assist the government in formulating policies that are appropriate for the present day.

\section{References}

Abbas, M.(2015). Evaluation of Factors affecting the Quality of Construction Projects. Technical Journal, University of Engineering and Technology (UET) Taxila, Pakistan, 2(1), 94-109.

Ali, S., Haider, Z., Munir, F., Khan, H., \& Ahmed, A. (2013). Factors contributing to the students academic performance: A case study of Islamia University Sub-Campus. American Journal of educational research, 1(8), 283-289.

Araque, H. A. (2009). Obstacles to the efficiency and performance of Saudi nurses at the Ministry of Health, study field Analytical: Region Riyadh. Riyadh. Ministry of Health.

Aseervatham, G. S. B., Sivasudha, T., Jeyadevi, R., \& Ananth, D. A. (2013). Environmental factors and unhealthy lifestyle influence oxidative stress in humans - an overview. Environmental Science and Pollution Research, 20(7), 4356-4369.

Baporikar, N. (Ed.). (2016). Innovation and Shifting Perspectives in Management Education. IGI Global.

Baron, R. M., \& Kenny, D. A. (1986). The moderator-mediator variable distinction in social psychological research: Conceptual, strategic, and statistical considerations. Journal of Personality and Social Psychology, 51(6), 1173-1185.

Bickford, D. J.(2006). Community: the hidden context of learning, in Oblinger (D.Ed.), Learning spaces, EDUCAUSE, Boulder, 4(30), 40-61.

Bill, M (2003). School leaders: changing roles and impact on. Education and Training, 5(3),1 1-25.

Byrne, B. M. (2010). Structural equation modeling with AMOS (2nd ed). New York: Routledge.

Castor, M. (2009). The use of structural equation modeling to describe the effect of operator functional state on air-to-air engagement outcomes. Linköping Studies in Science and Technology, Dissertation No. 1251.

El Ansari, W., \& Stock, C. (2010). Is the health and wellbeing of university students associated with their performance? Cross sectional findings from the United Kingdom. International Journal of Environmental Research and Public Health, 7(3), 509-527.

Esch, M., (2014). Personal, family, and academic factors affecting low achievement in secondary school. Electronic Journal of Research in Educational Psychology and Psychopedagogy,5(1),3245 . 
Evans, S. D., Hanlin, C. E., \& Prilleltensky, I. (2007). Blending ameliorative and transformative approaches in human service organizations: A case study. Journal of Community Psychology, 35(3), 329-346.

Fatima, S., Bashir, M., Khan, K., Farooq, S., Shoaib, S., \& Farhan, S. (2021). Effect of presence and absence of parents on the emotional maturity and perceived loneliness in adolescents. Journal of Mind and Medical Sciences, 8(2), 259-266.

Fenton, B. (2014). Workplace wellbeing programmes and their impact on employees and their employing organisations: A scoping review of the evidence base. A Collaboration between Health Exchange \& University of Birmingham, 11(27), 2014.

Ferdinand, A. (2006). Structural equation modeling dalam penelitian manajemen: aplikasi modelmodel rumit dalam penelitian untuk Tesis Magister \& Disertasi Doktor. Language, 3(390p), $24 \mathrm{~cm}$.

Ganasegeran, D.A. (2012). Social and psychological factors affecting eating habits among university students in a Malaysian medical school: a cross-sectional study. Nutrition Journal, 11(1), 1-7.

Gillespie, M. (2002). Student-teacher connection in clinical nursing education. Journal of advanced nursing, 37(6), 566-576.

Griggs, S., \& Crawford, S.L. (2017). Hope, core self-evaluations, emotional well-being, healthrisk behaviors, and academic performance in university freshmen. Journal of Psychosocial Nursing, 55(9), 33-42.

Hair, J., Hult, G. T. M., Ringle C., \& Sarstedt, M. (2006). Multivariate data analysis (6th ed.). New Jersey: Pearson Education International.

Hair Jr, J. F., Hult, G. T. M., Ringle, C. M., \& Sarstedt, M. (202 1). A primer on partial least squares structural equation modeling (PLS-SEM). Sage publications.

Henard, F., \& Leprince-Ringuet, S. (2008). The path to quality teaching in higher education. París: OCDE

Hussain, S. (2003). The factors that influence the acquisition of a second language. International Nursing Review, 6(1),86- 99.

Kaplan, B., \& Kaiser, R. (2006). The versatile leader: Make the most of your strengths without overdoing it (Vol. 309). John Wiley \& Sons.

Kline, R. B. (201 1). Principles and practices of structural equation modeling (2nd ed). New York: The Guilford Press.

Korhonen, L. (2014). Learning difficulties, academic well-being and educational dropout: A person-centred approach. Learning and Individual Differences, 31(1), 1-10.

Kuh, M. A. (2009). The relationship between learning approaches and learning outcomes: A study of Irish accounting students. AccountingEducation, 14(1), 44-65.

La Fountaine J. (2006). Wellness factors in first year college students. American Journal of Health Studies, 2(1), 214-218.

Maharaj, A. (2018). Wellness factors impacting student academic performance from a higher education perspective. Educor Multidisciplinary Journal, 2(1), 69-85. 
Mann, G., Kaiser, K., Trapp, N., Cafer, A., Grant, K., Gupta, K., \& Bolden, C. (202 1). Barriers, Enablers, and Possible Solutions for Student Wellness: A Qualitative Analysis of Student, Administrators, and Staff Perspectives. Journal of School Health, 91(12), 1002-1013.

Marica, M. (2007). Relationships Between School and Family. Qualitative Research, 2(2), 183-192.

Mushtaq, I., \& Khan, S. N. (2012). Factors affecting students' academic performance. Global journal of management and business research, 12(9), 17-22.

Najah, R. A. (2009). The Factors Influencing Students ${ }^{e}$ Performance at University Technology MARA Kedah. Management Science and Engineering,4(1), 117-124.

Nemec, E. C., Thomas, M. C., Gile, K. J., Tong, J., \& Mattison, M. J. (2019). Biometric Evaluation of PharmD Student Wellness and Academic Performance. American Journal of Pharmaceutical Education, 10(3) 212-227.

Norhadiya, M. A. (2016). The Factors Influencing Students ${ }^{e}$ Performance. Canadian Research $\Xi^{\circ}$ Development Center of Sciences and Cultures,14(2) 312-317.

Pallant, J. (2007). SPSS Survival Manual. Maideuhead, Berkshire. Open University Press.

Rehana, M. (2014). Social wellness: a positive energy for wellness. JPMI, 28(2) 65-71.

Reilly, E., Dhingra, K., \& Boduszek, D. (2014). Teachers ${ }^{e e}$ self-efficacy beliefs, self-esteem, and job stress as determinants of job satisfaction. International Journal of Educational Management, 28(4), 365-378.

Reynolds, A. R., \& Walberg, H. J. (1992). A process model of mathematics achievement and attitude. Journal of Research in Mathematics, 23(2), 306-328.

Robert, R. A. (2013). Opportunities for library partnerships on a university campus. University Libraries: Faculty Publications,2(1), 85-91.

Salzman, J., Williamson, M., Epsina-Rey, A., Kibble, J., \& Kauffman, C. (2021). Effects of voluntary attendance patterns on first-year medical students' wellness and academic performance during COVID-19. Advances in Physiology Education, 45(3), 634-643.

Sammons, P., Gu, Q., Day, C., \& Ko, J. (2011). Exploring the impact of school leadership on pupil outcomes. Results from a study of academically improved and effective schools in England. International Journal of Educational Management, 25(1),83-101.

Santoso, S. (2007). Konsep dan Aplikasi dengan AMOS. Elex Media Komputindo.

Shah, R., \& Goldstein, S. M. (2006). Use of structural equation modeling in operations management research: Looking back and forward. Journal of Operation Management, 24(2), 148-169.

Tahir, L. A. (2006). Factors affecting student ${ }^{\text {ee }}$ performance. Bangladesh e-Journal of Sociology, 12(1),67-79.

Todd, M. K. (2011). Handbook of medical tourism program development: Developing globally integrated health systems. CRC Press.

Topor, D. R., Keane, S. P., Shelton, T. L., \& Calkins, S. D. (2010). Parent involvement and student academic performance: A multiple mediational analysis. Journal of prevention $\mathcal{E}^{\circ}$ intervention in the community, 38(3), 183-197. 
Uemura, R., \& Rohrman S. (2012). Adolescent mental health, behavior problems, and academic achievement. Journal of Health and Social Behaviour, 53(3), 482-497.

Van Lingen, J. M., Van Douman, D. L., \& Van Wannenburg, I. (2011). A cross-sectional exploration of the relationship between undergraduate nursing student wellness and academic outcomes at a South African higher education institution. South African Journal of Psychology, 41(3), 396-408.

Walberg, H. J. (1981). A psychological theory of educational productivity. In F. H. Farley \& N. Gordon (Eds.), Psychological and Education,14(1), 81-110.

Walton, G. M., \& Cohen, G. L. (2011). A brief social-belonging intervention improves academic and health outcomes of minority students. Science, 331(6023), 1447-1451. 